\title{
Growth Dimensions of Long Staple Cotton Area, Production and Yield in Gujarat, India
}

\author{
Daud Mohammad*, R.L. Shiyani and N.J. Ardeshna \\ Department of Agricultural Economics, Junagadh Agriculture University, \\ Mota Bhandariya-Amreli, Gujarat, India \\ *Corresponding author
}

A B S T R A C T

Keywords

Long staple cotton, Area, Production, Yield, Growth rate, Percentage change, Instability indices, Decomposition

Article Info

Accepted:

20 April 2018

Available Online:

10 May 2018
Gujarat is one of the main cotton producing states in India, which ranks first in production and second in area in the country.This study was therefore, undertaken to study the growth dimensions of long staple cotton in Gujarat. The necessary time series data on area, production and yield were compiled from various official published sources for the period from 1980-81 to 2015-16. The trend of long staple cotton was examined with the compound growth rates and instability indices in Gujarat. The results revealed that there was an increase in average of area, production and yield of long staple cotton in all the three periods. In terms of percentage change, production noticed the highest per cent change during Post-Liberalization Period over Pre-Liberalization Period (538.23 \%). The highest instability $(43.97 \%)$ and the highest significant growth rate $(7.50 \%$ / annum) were observed in production of long staple cotton during Overall Period. The results revealed that the area and yield contributed jointly for the significant increase in cotton production during Overall Period. The results of Hazell's decomposition analysis showed that yield variance was the main contributor to the production variance in both Period I (50.9\%) and Period II $(83.34 \%)$ in the state.

\section{Introduction}

Cotton is the oldest of all fibers used by human beings and it forms one of the most important commercial crops playing a key role in the economy of the world. It is the leading textile fiber in the world accounting for 35 per cent of the world fiber use. Cotton was first cultivated about 7,000 years ago, by the inhabitants of the Indus Valley Civilization. This civilization covered a huge swath of the north-western part of the Indian sub-continent, comprising today parts of eastern Pakistan and north-western India (Mayilsami and Selvaraj, 2016).

Cotton often refers to as white gold or 'King' of fibre is an important commercial crop cultivated in India. Cotton, is one of the principal cash crops of India, contributes significantly to its economy and foreign exchange earnings. Approximately, 60 million 
people depend upon cotton production and related industries for their livelihoods. In fact, India has the largest area, which is approximately 34 per cent of the global area under cotton cultivation. However, in terms of productivity, sustainable production and consumption practices, the Indian cotton sector is facing some major challenges. Water is extensively required for cotton cultivation. Unfortunately, cotton farmers in India rely heavily on rainfed cultivation and it accounts for almost 70 per cent of the total area of cotton cultivation. Besides rainfall pattern, pest infestation has a significant effect on cotton cultivation in India. Bollworm and sucking pests have devastated cotton crops for years. Despite the fact that cotton occupies only five per cent of India's total cultivable land, approximately 50 per cent of pesticides used in India are consumed by cotton cultivation (Singh et al., 2013).

In India, cotton is grown in three diverse agroecological zones viz., North Zone which includes Punjab, Haryana and Rajasthan, Centre Zone comprising of Maharashtra, Gujarat and Madhya Pradesh and South Zone comprising of Andhra Pradesh, Karnataka and Tamil Nadu. In the recent period, cotton is gaining momentum in non- traditional areas such as Odisha, West Bengal and Tripura (Anon., 2017). Cotton, mostly known for its direct commercial use, has other uses as well, including being a part of human and animal consumables. Cotton is used to make fibers, which in turn are used to make thread, which then is woven into clothing. In addition, cotton seeds are crushed and squeezed for oil, which is found in a variety of processed foods consumed by human bodies (Singh et al., 2013).

\section{Materials and Methods}

For studying the growth dimensions of long staple cotton, Gujarat state was purposively selected as it is one of the major cotton producing states in India. The study was undertaken using secondary sources and the necessary time series data were compiled for the period from 1980-81 to 2015-16. The secondary data on area, production and yield of long staple cotton in Gujarat collected from various published sources viz., publications Ministry of Agriculture (MoA) and Farmers' Welfare, Government of India, Cotton Corporation of India (CCI). The time series data were obtained for a period of 36 years (1980-81 to 2015-16) which was further divided into three sub-periods as Preliberalization Period from 1980-81 to 1991-92, Liberalization Period from 1992-93 to 200304 Post-liberalization Period from 2004-05 to 2015-16 and Overall Period from 1980-81 to 2015-16.

The trend of growth dimensions of long staple cotton area, production and yield was examined with the compound growth rates and instability indices in Gujarat.

\section{Compound growth rate analysis}

Growth rate can be defined as the rate of change per unit time (Nandamohan and Sunny, 1993). It is used to measure the past performance of the economic variables in question and describe the trends in those variables over time. The normal statistical procedure to obtain a measure of growth dynamics of crops over a period is to postulate a hypothetical function which would adequately describe the series of economic variables over time and estimate their parameters. The growth in the area, production and yield of long staple cotton was estimated using the exponential growth function of the form:

$Y_{t}=a b^{t} e^{u t}$

Where, 
$\mathrm{Y}_{\mathrm{t}}$ : Dependent variable (Area/ Production/ Productivity) for which growth rate is estimated;

a: Intercept;

b: Regression coefficient;

t: Years which take values, 1, 2,,n;

$\mathrm{u}_{\mathrm{t}}$ : Disturbance term for the year $\mathrm{t}$.

The equation was transformed into log linear form for estimation purpose and was estimated using Ordinary Least Square (OLS) technique. The compound growth rate $(\mathrm{g})$ in percentage was then computed from the relationship,

$g=($ Antilog of $\log b-1) * 100$

The significance of the regression coefficient was tested by using the students ' $\mathrm{t}$ ' test.

\section{Instability index}

The agricultural instability can be measured by different methods, such as the Coefficient of Variation (CV), dispersion, Cuddy Della Valle Index (CDI), etc. In the present study, the Cuddy Della Valle Index was applied for measuring the instability in growth dimensions in area, production and productivity of long staple cotton in Gujarat. It is estimated as follows:

Estimate the parameter of a log-linear trend line for the variable $\left(Y_{t}\right)$ for which instability is to be estimated

If the estimated parameter is statistically significant, then the instability index (IIN) is defined as

$\mathrm{IIN}=\mathrm{CV} \mathrm{X}\left(1-\mathrm{r}^{2}\right)^{0.5}$

Where,
$\mathrm{CV}=$ Coefficient of variation;

$\mathrm{r}^{2}=$ Coefficient of determination;

$\mathrm{CV}=(\mathrm{SD} /$ Mean $) \mathrm{X} 100$.

Where,

$\mathrm{SD}=$ Standard deviation

\section{Instability in production}

In order to examine the sources of instability, the area and yield data for long staple cotton crop are detrended (Hazell, 1982) using linear equation of the following form:

$$
Z_{t}=a+b t+u_{t}(1)
$$

Where,

$\mathrm{Z}_{\mathrm{t}}=$ dependent variable (Area / Productivity);

$\mathrm{a}=$ intercept;

$\mathrm{b}=$ parameter to be estimated;

$\mathrm{t}=$ time variable (in years);

$\mathrm{u}_{\mathrm{t}}=$ error term with usual assumptions.

After detrending, the residuals are centered on the mean area or yield for each period $\mathrm{z}$, resulting in detrended time series data of the form:

$\mathrm{Z}=\mathrm{ut}+\mathrm{Z}(2)$

The time series data on detrended production for long staple cotton crop are then calculated as the product of the detrended areas and yields. Further, variance of production is decomposed into its constituent sources viz. area variance, yield variance, area-yield covariance and higher order interaction area and yield to examine the source of instability. Let $\mathrm{Q}$ denote production, A the area sown and Y, yield. Then for long staple cotton crop 
$\mathrm{V}(\mathrm{Q})={ }^{\bar{A} 2} \mathrm{~V}(\mathrm{Y})+{ }^{\bar{Y}_{2}} \mathrm{~V}(\mathrm{~A})+2^{\bar{A} \bar{Y}} \operatorname{Cov}(\mathrm{A}$, $\mathrm{Y})-\operatorname{Cov}(\mathrm{A}, \mathrm{Y})^{2}+\mathrm{R}(3)$

Where,

$\mathrm{V}(\mathrm{Q})=$ production variance;

$\bar{A}=$ mean area;

$\bar{Y}=$ mean yield;

$\mathrm{V}(\mathrm{Y})=$ yield variance;

$\mathrm{V}(\mathrm{A})=$ area variance;

$\operatorname{Cov}(\mathrm{A}, \mathrm{Y})=$ Area - yield co-variance;

$\operatorname{Cov}(\mathrm{A}, \mathrm{Y})^{2}=$ Higher order co-variance between area and yield;

$\mathrm{R}=$ Residual.

The above equation is not only a function of variances of yields and areas sown, but also the mean area and yield of co-variance between areas and yields.

Clearly, a change in any one of these components would lead to a change in V $(\mathrm{Q})$ between two periods of time. The change in variance of production $\Delta \mathrm{V}(\mathrm{Q})$ can be decomposed as given in the following equations 18 to 22. Methods of decomposition of the changes in variance of production is carried out by constructing a method to partition the changes in variance of production $(\mathrm{V}(\mathrm{Q}))$ between the first and the second periods into its constituent parts. As shown in Eq. (3), the variance of production, $V(Q)$ can be expressed as,

$\mathrm{V}(\mathrm{AY})={ }^{\overline{\mathrm{A}} 2} \mathrm{~V}(\mathrm{Y})+{ }^{\overline{\mathrm{Y}}_{2}} \mathrm{~V}(\mathrm{~A})+2^{\overline{\mathrm{A}}^{\bar{Y}}} \operatorname{cov}(\mathrm{A}$, $\mathrm{Y})-\operatorname{cov}(\mathrm{A}, \mathrm{Y})^{2}+\mathrm{R}$

Using Eq. (3), variance of production in the first period is

$\mathrm{V}\left(\mathrm{P}_{1}\right)=\overline{\mathrm{A}}_{1}^{2} \mathrm{~V}\left(\mathrm{Y}_{1}\right)+\overline{\mathrm{Y}}_{1}{ }^{2} \mathrm{~V}\left(\mathrm{~A}_{1}\right)+2 \overline{\mathrm{A}}_{1} \overline{\mathrm{Y}}_{1} \mathrm{cov}$ $\left(A_{1}, Y_{1}\right)-\operatorname{cov}\left(A_{1}, Y_{1}\right)^{2}+R_{1}(4)$

And in the second period is
$\mathrm{V}\left(\mathrm{P}_{2}\right)=\overline{\mathrm{A}}_{2}^{2} \mathrm{~V}\left(\mathrm{Y}_{2}\right)+\overline{\mathrm{Y}}_{2}{ }^{2} \mathrm{~V}\left(\mathrm{~A}_{2}\right)+2 \overline{\mathrm{A}}_{2} \overline{\mathrm{Y}}_{2} \mathrm{cov}$ $\left(A_{2}, Y_{2}\right)-\operatorname{cov}\left(A_{2}, Y_{2}\right)^{2}+R_{2}(5)$

Each variable in the second period can be expressed as its counterpart in the first period plus the change in the variable between the two periods, i.e.,

$\overline{\mathrm{A}}_{2}=\overline{\mathrm{A}}_{1}+\Delta^{\overline{\mathrm{A}}}$

$\overline{\mathrm{Y}}_{2}=\overline{\mathrm{Y}}_{1+\Delta}+\overline{\mathrm{Y}}$

$\mathrm{V}\left(\mathrm{A}_{2}\right)=\mathrm{V}\left(\mathrm{A}_{1}\right)+\Delta \mathrm{V}(\mathrm{A})$

$\mathrm{V}\left(\mathrm{Y}_{2}\right)=\mathrm{V}\left(\mathrm{Y}_{1}\right)+\Delta \mathrm{V}(\mathrm{Y})$

$\operatorname{Cov}\left(A_{2}, Y_{2}\right)=\operatorname{Cov}\left(A_{1}, Y_{1}\right)+\Delta \operatorname{Cov}\left(A_{1}, Y_{1}\right)$

Eq. (5) can, therefore, be rewritten as

$\mathrm{V}\left(\mathrm{P}_{2}\right)=\left\{\bar{A}_{1}+\Delta^{\bar{A}}\right\}_{2}\left\{\mathrm{~V}\left(\mathrm{Y}_{1}\right)+\Delta \mathrm{V}(\mathrm{Y})\right\}+$ $\left\{\bar{Y}_{1}+\Delta^{\bar{Y}_{2}}\right\}\left\{\mathrm{V}\left(\mathrm{A}_{1}\right)+\Delta \mathrm{V}(\mathrm{A})\right\}+2\left\{\bar{A}_{1}+\right.$ $\left.\Delta^{\bar{A}}\right\}\left\{{ }_{1}{ }_{1}+\Delta^{\bar{Y}}\right\}\left\{\operatorname{cov}\left(\mathrm{A}_{1}, \mathrm{Y}_{1}\right)+\Delta \operatorname{cov}(\mathrm{A}, \mathrm{Y})\right\}$ $-\left\{\operatorname{cov}\left(\mathrm{A}_{1}, \mathrm{Y}_{1}\right)+\Delta \operatorname{cov}(\mathrm{A}, \mathrm{Y})\right\}^{2}+\left\{\mathrm{R}_{1}+\Delta \mathrm{R}\right\}$

(6)

Which can be expressed as

$\mathrm{V}\left(\mathrm{P}_{2}\right)={ }^{\bar{A}}{ }_{1}^{2} \mathrm{~V}\left(\mathrm{Y}_{1}\right)+\Delta^{\bar{A}{ }^{2}} \mathrm{~V}\left(\mathrm{Y}_{1}\right)+2^{\bar{A}}{ }_{1} \Delta^{\bar{A}} \mathrm{~V}$ $\left(\mathrm{Y}_{1}\right)+{ }^{\bar{A}}{ }_{1}{ }_{1} \Delta \mathrm{V}(\mathrm{Y})+\Delta^{\bar{A}}{ }^{2} \Delta(\mathrm{Y})+2{ }^{\bar{A}}{ }_{1} \Delta^{\bar{A}} \Delta \mathrm{V}$ $(\mathrm{Y})+{ }^{\bar{Y}}{ }_{1}{ }^{2} \mathrm{~V}\left(\mathrm{~A}_{1}\right)+\Delta^{\bar{Y}_{2}} \mathrm{~V}\left(\mathrm{~A}_{1}\right)+2^{\bar{Y}}{ }_{1} \Delta^{\bar{Y}} \mathrm{~V}$ $\left(\mathrm{A}_{1}\right)+\bar{Y}_{1}{ }_{1} \Delta \mathrm{V}(\mathrm{A})+\Delta^{\bar{Y}_{2}} \Delta \mathrm{V}(\mathrm{A})+2{ }^{\bar{Y}}{ }_{1} \Delta^{\bar{Y}} \Delta$ $\mathrm{V}(\mathrm{A})+2 \overline{\mathrm{A}}_{1} \overline{\mathrm{Y}}_{1} \mathrm{cov}\left(\mathrm{A}_{1}, \mathrm{Y}_{1}\right)+2 \bar{A}_{1} \bar{Y}_{\mathrm{Cov}}$ $\left(\mathrm{A}_{1}, \mathrm{Y}_{1}\right)+2^{\bar{Y}}{ }_{1} \Delta^{\bar{A}} \operatorname{cov}\left(\mathrm{A}_{1}, \mathrm{Y}_{1}\right)+2 \Delta^{\bar{A}} \Delta^{\bar{Y}} \mathrm{cov}$ $\left(\mathrm{A}_{1}, \mathrm{Y}_{1}\right)+2{ }^{\overline{\mathrm{A}}} \overline{ }_{1}{ }_{1} \Delta \operatorname{cov}(\mathrm{A}, \mathrm{Y})+2 \bar{A}_{1} \Delta \bar{Y}_{\Delta \mathrm{cov}}$ $(\mathrm{A}, \mathrm{Y})+2 \bar{Y}_{1} \Delta^{\bar{A}} \Delta \operatorname{cov}(\mathrm{A}, \mathrm{Y})+2 \Delta^{\bar{A}} \Delta^{\bar{Y}} \Delta \mathrm{cov}$ $(\mathrm{A}, \mathrm{Y})-\left\{\operatorname{cov}\left(\mathrm{A}_{1}, \mathrm{Y}_{1}\right)\right\}^{2}-\{\Delta \operatorname{cov}(\mathrm{A}, \mathrm{Y})\}^{2}-2$ $\operatorname{cov}\left(\mathrm{A}_{1}, \mathrm{Y}_{1}\right) \Delta \operatorname{cov}(\mathrm{A}, \mathrm{Y})+\mathrm{R}_{1}+\Delta \mathrm{R}(7)$

The change in variance of production, $\Delta \mathrm{V}(\mathrm{P})$ is then obtained by subtracting Eq. (4) from Eq. (7). Thus,

$\Delta \mathrm{V}(\mathrm{P})=\mathrm{V}\left(\mathrm{P}_{2}\right)-\mathrm{V}\left(\mathrm{P}_{1}\right)=\Delta^{\overline{\mathrm{A}} 2} \mathrm{~V}\left(\mathrm{Y}_{1}\right)+2$ $\overline{\mathrm{A}}_{1} \Delta \overline{\mathrm{A}}_{\mathrm{V}}\left(\mathrm{Y}_{1}\right)+{ }^{\mathrm{A}_{1}}{ }_{1} \Delta \mathrm{V}(\mathrm{Y})+\Delta{ }^{\overline{\mathrm{A}}} 2 \Delta \mathrm{V}(\mathrm{Y})+2$ 
$\bar{A}_{1} \Delta^{\overline{\mathrm{A}} \Delta} \mathrm{V}(\mathrm{Y})+\Delta{ }^{\overline{\mathrm{Y}}_{2}} \mathrm{~V}\left(\mathrm{~A}_{1}\right)+2{ }^{\overline{\mathrm{Y}}}{ }_{1} \Delta^{\overline{\mathrm{Y}}} \mathrm{V}\left(\mathrm{A}_{1}\right)+$ $\overline{\mathrm{Y}}_{1}{ }_{1} \Delta \mathrm{V}(\mathrm{A})+\Delta \overline{\mathrm{Y}}_{2} \Delta \mathrm{V}(\mathrm{A})+2 \overline{\mathrm{Y}}_{1} \Delta{ } \overline{\mathrm{Y}} \Delta \mathrm{V}(\mathrm{A})+$

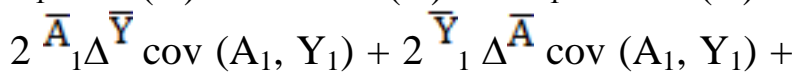
$2 \Delta^{\overline{\mathrm{A}} \Delta \overline{\mathrm{Y}}_{\mathrm{Y}}} \operatorname{cov}\left(\mathrm{A}_{1}, \mathrm{Y}_{1}\right)+2 \overline{\mathrm{A}}_{1} \overline{\mathrm{Y}}_{1} \Delta \operatorname{cov}(\mathrm{A}, \mathrm{Y})+$

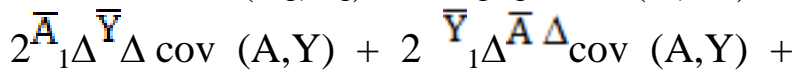
$2 \Delta^{\overline{\mathrm{A}} \Delta \overline{\mathrm{Y}}} \Delta \operatorname{cov}(\mathrm{A}, \mathrm{Y})-\{\Delta \operatorname{cov}(\mathrm{A}, \mathrm{Y})\}^{2}-2 \mathrm{cov}$ $\left(\mathrm{A}_{1}, \mathrm{Y}_{1}\right) \Delta \operatorname{cov}(\mathrm{A}, \mathrm{Y})+\Delta \mathrm{R}(8)$

Similarly, the decomposition of the change in variance into ten components can also be given in the form of the Table 1.

\section{Results and Discussion}

From the results depicted in the Table 2, it can be observed that the average area under long staple cotton crop has been increasing in Gujarat since 1980-81. The average area during the Pre-Liberalization Period (19801992) was 12.67 lakh hectares which increased to 14.78 lakh hectares during Liberalization Period (1992-2004) and it further increased to 24.75 lakh hectares during Post-Liberalization Period (2004-2016).The percentage change in area of long staple cotton during Liberalization Period over PreLiberalization Period was 16.67 per cent which increased by fourfold (67.46\%) during Post-Liberalization Period over Liberalization Period and it further increased to fifth fold (95.37\%) during Post-Liberalization Period over Pre-Liberalization Period.

The average production of long staple cotton crop has been increasing in Gujarat since 1980-81 (Table 2). During Pre-Liberalization Period (1980-1992), the average production of long staple cotton crop was found to be 14.98 lakh bales each of $170 \mathrm{~kg}$ which increased to 25.68 lakh bales during Liberalization Period (1992-2004) and it further increased to 95.60 lakh bales during Post-Liberalization Period (2004-2016). The results also indicated that during Liberalization Period over Pre-
Liberalization Period, the percentage increase in production was 71.48 per cent while it increased by about fourfold (272.18\%) during Post-Liberalization Period over Liberalization Period which further increased to more than seven fold (538.23 \%) during PostLiberalization Period.

At the same time, there has been increasing in the average yield of long staple cotton crop in Gujarat since 1980-81. The average productivity of long staple cotton crop was observed to be $197.62 \mathrm{~kg} / \mathrm{ha}$ during PreLiberalization Period (1980-1992) which increased to $302.94 \mathrm{~kg} / \mathrm{ha}$ during Liberalization Period (1992-204) and was further increased to $651.08 \mathrm{~kg} / \mathrm{ha}$ during PostLiberalization Period (2004-2016). Whereas the percentage increases in yield of long staple cotton was 49.09 per cent during Liberalization Period over Pre-Liberalization Period while it increased more than double (114.92 \%), during Post-Liberalization Period over Liberalization Period. It further increased to more than fourfold $(229.46 \%)$ during PostLiberalization Period over Pre-Liberalization Period. The highest percentage change $(538.23 \%)$ was observed in production of long staple cotton during the PostLiberalization Period over Pre-Liberalization Period.

The results revealed that there was an increase in average of area, production and productivity of long staple cotton in all the three periods. The highest productivity of cotton was noticed during Post-Liberalization Period (2004-2016) which was $651.08 \mathrm{~kg} / \mathrm{ha}$. It may be due to the adoption of $\mathrm{B}_{\mathrm{t}}$. cotton, regular rainfall during these years, increase in irrigation facilities and entrepreneurial skill of the farmers.

These findings are in line with those of Samuel et al., (2015) who observed that the percentage change in terms of area, production 
and productivity of cotton in Gujarat was to the tune of 47.95, 174.96 and 75.99 per cent, respectively during the Period II over the Period I and the contribution of yield to production was relatively more than that of the contribution of area.

\section{Trend in growth dimensions}

The instability indices of growth dimensions in area, production and productivity of long staple cotton crop in Gujarat state during the study period are presented in Table 3 . It can be revealed from Table 3, that the instability in growth dimensions in terms of area was higher during Overall Period $(18.64 \%)$ than the instability observed during Pre-Liberalization (13.05\%), Liberalization $(6.16 \%)$ and PostLiberalization Period $(7.88 \%)$. At the same time, the instability in terms of production were found to be low during Postliberalization period $(16.93 \%)$, but it was higher during pre-liberalization period (30.19\%), liberalization period (38\%) and overall period (43.97\%). Production variability in cotton was increased during Liberalization Period from 30.19 to 38.00 per cent. This was mainly attributed to increase in yield variability in cotton during same period. Similarly, the instability of productivity was exhibited to be low during Post-Liberalization Period (14.18\%), but it was high during PreLiberalization (28.11\%), Overall Period (28.29\%) and Liberalization (30.93\%).

A perusal of the table revealed that the yield of long staple cotton crop was more unstable than its area in all the study periods. The variability in cotton area considerably reduced whereas the yield variability slightly increased during liberalization period as compared to the pre-liberalization period. Suresh et al., (2013) reported that, due to high spread of Bt cotton, instability in cotton area has reduced, which supports our findings. It was further noticed that, yield variability is a prime source of instability in production of long staple cotton crop and area variability has been seen as secondary source of instability.

It is worth mentioning that the fluctuation in area under cotton cultivation seemed to be more stable when compared to that of production and productivity. The results revealed that high level of instability in production was noticed throughout the study period in Gujarat State. Since a major part of acreage under long staple cotton is under rainfed regions, the fluctuations in rainfall would have in turn led to fluctuations in production levels. Production is the results of both area and yield; hence its instability index is higher than that of area and yield. These findings are in line with those of Sharma, (2015) who observed that the fluctuation in terms of area, production and productivity of cotton in India was to the tune of $13.63,72.45$ and 55.16 per cent, respectively during overall decade.

The results are also supported by the findings of More et al., (2017) who also observed that the magnitude of instability in area, production and productivity of cotton was 25.78, 54.12 and 32.34 per cent, during entire study period in the Gujarat state.

\section{Growth rate in long staple cotton cultivation}

The trends in growth dimensions of long staple cotton crop in Gujarat state during the study period are given in the Table 4. The compound growth rate of area under cotton was negative (- $4.44 \%$ / annum) and significant at 5 per cent level during PreLiberalization Period while during Liberalization, Post-Liberalization and Overall Periods, corresponding figures were noticed to be positive and highly significant with the magnitude of 3.84, 3.01 and 2.65 per cent per annum, respectively. It is apparent from Table 
4 that the compound growth rate for long staple cotton production showed a negative growth rate during Pre-Liberalization Period (-4.67\% / annum).

The production of long staple cotton during Pre-Liberalization Period has recorded significant negative trend in the state due to significant reduction in area of cotton in the same period. More et al., (2017) also reported that production of cotton during first subperiod (1970-71 to 1989-90) has recorded significant negative trend in all the districts of the state due to noteworthy reduction in area of cotton.

This gives confirmation to our results. It was positive but non-significant (3.59\% / annum) in case of Liberalization Period. However, it is worth mentioning that it was found positive and highly significant during PostLiberalization (5.16 \% / annum) and Overall Period (7.50 \% / annum). The area expansion under cotton led to increase cotton production during post-liberalization period. But in case of the overall period, area and yield contributed jointly for the significant increase in cotton production.

The results indicated that, the compound growth rate for long staple cotton productivity in Gujarat was negative in Pre-Liberalization Period (-0.24 \% / annum), while it experienced positive but non-significant compound growth rate i.e. 0.91 and 2.07 per cent per annum, respectively during Liberalization and Post-Liberalization Periods, whereas positive and significant compound growth rate was observed during Overall Period (4.77 \% / annum). The results are in conformity with the findings of Mehta, (2012) also reported that the single most important factor of the widespread adoption of $B t$ cotton resulted in growth of area and productivity have combined to cause production growth rate of 15.4 per cent during the period 2000-01 to 2010-11 in Gujarat. He further noticed that the measures such as water harvesting through checkdams and water availability from Narmada project and other irrigation projects pursued by the state, have aided the shifts towards cotton quite significantly.

Ardeshna et al., (2017) who also observed that the area, production and yield of cotton increased at the rate of $1.19,4.49$ and 3.26 per cent, respectively during $1971-72$ to $2015-16$ in Gujarat state.

To sum up, it is useful to classify the above findings of growth rates and instability indices of area, production and yield into different classes. So, we can easily infer based on that the situation which is desirable for farmers can be taken into consideration and undesirable situation can be avoided.

These findings are summarised as under:

Level of growth rate or instability index $=$ $\bar{X} \pm 0.5 S D$

High growth and high instability: $\geq$ $\bar{X}+0.5 S D$

Medium growth and medium instability: $\leq$ $\bar{X}+0.5 S D$

Low growth and low instability: $\leq$ $\bar{X}-0.5 S D$

From the summary of findings presented in the Table 5, it can be concluded that the high growth rate with high instability was observed in production of cotton in Gujarat during Overall Period, while the high growth rate with low instability was recorded in the area of cotton during Liberalization Period and the high growth rate with medium instability was recorded in case of productivity during Overall Period. 
Table.1 Components of change in the variance of production

\begin{tabular}{|c|c|c|}
\hline Change in mean yield & $\Delta \overline{\mathrm{Y}}$ & $\begin{array}{c}2 \overline{\mathrm{A}}_{1} \Delta \overline{\mathrm{Y}} \operatorname{cov}\left(\mathrm{A}_{1}, \mathrm{Y}_{1}\right)+\left\{2 \overline{\mathrm{Y}}_{1} \Delta \overline{\mathrm{Y}} \Delta(\Delta \overline{\mathrm{Y}})^{2}\right\} \\
\mathbf{V}\left(\mathrm{A}_{1}\right)\end{array}$ \\
\hline Change in mean area & $\Delta \bar{A}$ & $\begin{array}{c}2 \overline{\mathrm{Y}}_{1} \Delta \overline{\mathrm{A}} \operatorname{cov}\left(\mathrm{A}_{1}, \mathrm{Y}_{1}\right)+\left\{2 \overline{\mathrm{A}}_{1} \Delta \overline{\mathrm{A}} \Delta(\Delta \overline{\mathrm{A}})^{2}\right\} \\
\mathrm{V}\left(\mathrm{Y}_{1}\right)\end{array}$ \\
\hline $\begin{array}{l}\text { Change in yield } \\
\text { variance }\end{array}$ & $\Delta \mathrm{V}(\mathrm{Y})$ & $\overline{\mathrm{A}}_{1}^{2} \Delta \mathrm{V}(\mathrm{Y})$ \\
\hline $\begin{array}{l}\text { Change in } \\
\text { areavariance }\end{array}$ & $\Delta \mathrm{V}(\mathrm{A})$ & $\overline{\mathrm{Y}}_{1}^{2} \Delta \mathrm{V}(\mathrm{A})$ \\
\hline $\begin{array}{l}\text { Interaction between } \\
\text { changes in mean yield } \\
\text { and mean area }\end{array}$ & $\Delta \overline{\mathrm{A}} \Delta \overline{\mathrm{Y}}$ & $2 \Delta \overline{\mathrm{A}} \Delta \overline{\mathrm{Y}} \operatorname{cov}\left(\mathrm{A}_{1}, \mathrm{Y}_{1}\right)$ \\
\hline $\begin{array}{l}\text { Change in area-yield } \\
\text { covariance }\end{array}$ & $\Delta \operatorname{cov}(\mathrm{AY})$ & $\begin{array}{c}\left\{2 \overline{\mathrm{A}}_{1} \overline{\mathrm{Y}}_{1}-2 \operatorname{cov}\left(\mathrm{A}_{1}, \mathrm{Y}_{1}\right)\right\} \Delta \operatorname{cov}(\mathrm{A}, \mathrm{Y}) \Delta\{\Delta \operatorname{cov} \\
(\mathrm{A}, \mathrm{Y})\}^{2}\end{array}$ \\
\hline $\begin{array}{l}\text { Interaction between } \\
\text { changes in mean area } \\
\text { and yield variance }\end{array}$ & $\Delta \overline{\mathrm{A}} \Delta \mathrm{V}(\mathrm{Y})$ & $\left\{2 \overline{\mathrm{A}}_{1} \Delta \overline{\mathrm{A}} \Delta(\Delta \overline{\mathrm{A}})^{2}\right\} \Delta \mathrm{V}(\mathrm{Y})$ \\
\hline $\begin{array}{l}\text { Interaction between } \\
\text { changes in yields and } \\
\text { area variance }\end{array}$ & $\Delta \overline{\mathrm{Y}} \Delta \mathrm{V}(\mathrm{A})$ & $\left\{2 \overline{\mathrm{Y}}_{1} \Delta \overline{\mathrm{Y}} \Delta(\Delta \overline{\mathrm{Y}})^{2}\right\} \Delta \mathrm{V}(\mathrm{A})$ \\
\hline $\begin{array}{l}\text { Interaction between } \\
\text { changes in mean area } \\
\text { and yield and changes } \\
\text { in area-yield } \\
\text { covariance }\end{array}$ & $\begin{array}{c}\Delta \overline{\mathrm{A}} \Delta \overline{\mathrm{Y}} \\
\Delta \operatorname{cov}(\mathrm{A})\end{array}$ & $\left(2 \overline{\mathrm{A}}_{1} \Delta \overline{\mathrm{Y}} \Delta 2 \overline{\mathrm{Y}}_{1} \Delta \overline{\mathrm{A}} \Delta 2 \Delta \overline{\mathrm{A}} \Delta \overline{\mathrm{Y}}\right) \Delta \operatorname{cov}(\mathrm{A}, \mathrm{Y})$ \\
\hline
\end{tabular}

Table.2 Period-wise percentage change of area, production and productivity of long staple cotton in Gujarat

(Per cent)

\begin{tabular}{|c|c|c|c|c|c|c|}
\hline & \multicolumn{3}{|c|}{ A verage } & \multicolumn{3}{c|}{ \% change } \\
& $\begin{array}{c}\text { Pre-Lib. } \\
(1980 \text { to } \\
1992)\end{array}$ & $\begin{array}{c}\text { Lib. } \\
(1992 \text { to } \\
2004)\end{array}$ & $\begin{array}{c}\text { Post-Lib. } \\
(2004 \text { to } \\
2016)\end{array}$ & $\begin{array}{c}\text { Period-II } \\
\text { over } \\
\text { Period-I }\end{array}$ & $\begin{array}{c}\text { Period-III } \\
\text { over } \\
\text { Period-II }\end{array}$ & $\begin{array}{c}\text { Period-III } \\
\text { over } \\
\text { Period-I }\end{array}$ \\
\hline $\begin{array}{c}\text { Area } \\
\text { (Lakh ha) }\end{array}$ & 12.67 & 14.78 & 24.75 & 16.67 & 67.46 & 95.37 \\
\hline $\begin{array}{c}\text { Production } \\
\text { (Lakh } \\
\text { bales) }\end{array}$ & 14.98 & 25.68 & 95.60 & 71.48 & 272.18 & 538.23 \\
\hline $\begin{array}{c}\text { Yeld } \\
\text { Kg/ha) }\end{array}$ & 197.62 & 302.94 & 651.08 & 49.09 & 114.92 & 229.46 \\
\hline
\end{tabular}

Note: Pre-Lib. $=$ Pre-Liberalization, Lib. $=$ Liberalization and Post-Lib. $=$ Post-Liberalization, Lha $=$ Lakh hectares, Lbales $=$ Lakh bales $(1 \mathrm{bale}=170 \mathrm{~kg})$. 
Table.3 Instability indices of growth dimensions of long staple cotton in Gujarat

\begin{tabular}{|c|}
\hline Period \\
\hline Pre-Liberalization \\
(1980-1992) \\
\hline Liberalization \\
(1992-2004) \\
\hline Post-Liberalization \\
(2004-2016) \\
\hline Overall Period \\
(1980-2016) \\
\hline
\end{tabular}

\begin{tabular}{|c|c|c|}
\hline Area & Production & Yield \\
\hline 13.05 & 30.19 & 28.11 \\
\hline 6.16 & 38.00 & 30.93 \\
\hline 7.88 & 16.93 & 14.18 \\
\hline 18.64 & 43.97 & 28.29 \\
\hline
\end{tabular}

Table.4 Trends in growth dimensions of long staple cotton in Gujarat

(\% per annum)

\begin{tabular}{|c|c|c|c|}
\hline \multirow{2}{*}{ Period } & Area & Production & Yield \\
\hline $\begin{array}{c}\text { Pre-Liberalivation } \\
\text { (1980-1992) }\end{array}$ & CGR & CGR & CGR \\
\hline $\begin{array}{c}\text { Liberalization } \\
\text { (1992-2004) }\end{array}$ & $3.44 * *$ & -4.67 & -0.24 \\
\hline $\begin{array}{c}\text { Post-Liberalization } \\
\text { (2004-2016) }\end{array}$ & $3.01 * *$ & 3.59 & 0.91 \\
\hline $\begin{array}{c}\text { Overall Period } \\
\text { (1980-2016) }\end{array}$ & $2.65 * *$ & $5.16 *$ & 2.07 \\
\hline
\end{tabular}

Note:

1. LGR=Linear Growth Rate and CGR= Compound Growth Rate;

2. * Indicates significant at 5\% and ** Indicates significant at $1 \%$

Table.5 Classification of compound growth rates and instability indices of long staple cotton area, production and yield in Gujarat

\begin{tabular}{|l|c|c|c|}
\hline \multicolumn{1}{c}{$\begin{array}{c}\text { Level of classification } \\
\text { High growth and high instability }\end{array}$} & $\begin{array}{c}\text { Area } \\
\text { (Lakh ha) }\end{array}$ & $\begin{array}{c}\text { Production } \\
\text { (Lakh bales) }\end{array}$ & $\begin{array}{c}\text { Yield } \\
\text { (Kg/ha) }\end{array}$ \\
\hline High growth and medium instability & - & P-IV & - \\
\hline High growth and low instability & P-II & - & P-IV \\
\hline Medium growth and high instability & P-IV & - & - \\
\hline Medium growth and medium instability & - & P-II & P-II \\
\hline Medium growth and low instability & P-III & P-III & P-III \\
\hline Low growth and high instability & - & - & - \\
\hline Low growth and medium instability & P-I & P-I & P-I \\
\hline Low growth and low instability & - & - & - \\
\hline
\end{tabular}

Note: P-I, P-II, P-III and P-IV denotes Pre-Liberalization, Liberalization, Post-Liberalization and Overall Periods, respectively. 
Table.6 Sources of variance in long staple cotton production

\begin{tabular}{|l|l|l|c|c|c|c|}
\hline Period & $\begin{array}{l}\text { Area } \\
\text { variance } \\
\text { V(A) }\end{array}$ & $\begin{array}{l}\text { Yield } \\
\text { variance } \\
\text { V(Y) }\end{array}$ & $\begin{array}{l}\text { Area-yield } \\
\text { covariance } \\
\text { Cov }(\mathbf{A}, \mathbf{Y})\end{array}$ & $\begin{array}{l}\text { Higher } \\
\text { order } \\
\text { interaction } \\
\text { Cov (A,Y) }\end{array}$ & $\begin{array}{l}\text { Residual } \\
\text { R }\end{array}$ & Total \\
\hline $\begin{array}{l}\text { Period I } \\
(\mathbf{1 9 8 0 - 1 9 9 8 )})\end{array}$ & 28.34 & 50.90 & 43.21 & 4.95 & -17.50 & 100.00 \\
\hline $\begin{array}{l}\text { Period II } \\
(\mathbf{1 9 9 8 - 2 0 1 6 )}\end{array}$ & 7.81 & 83.34 & 9.90 & 0.37 & -0.68 & 100.00 \\
\hline
\end{tabular}

Note: $\mathrm{A}=$ Area; $\mathrm{Y}=$ Yield; $\mathrm{Cov}=$ Covariance and $\mathrm{R}=$ Residual.

Table.7 Components of change in the variance of production of long staple cotton in Gujarat

(In per cent)

\begin{tabular}{|l|c|c|}
\hline \multicolumn{1}{|c|}{ Sources of change } & Symbol & Percent of change \\
\hline Change in mean yield & $\Delta \bar{Y}$ & 14.78 \\
\hline Change in mean area & $\Delta \bar{A}$ & 9.52 \\
\hline Change in yield variance & $\Delta \mathrm{V}(\mathrm{Y})$ & 0.42 \\
\hline Change in area variance & $\Delta \mathrm{V}(\mathrm{A})$ & 2.09 \\
\hline $\begin{array}{l}\text { Interaction between changes in mean yield and } \\
\text { mean area }\end{array}$ & $\Delta \bar{A} \Delta \bar{Y}$ & 3.24 \\
\hline Change in area-yield covariance & $\Delta \operatorname{cov}(\mathrm{AY})$ & -0.62 \\
\hline $\begin{array}{l}\text { Interaction between changes in mean area and } \\
\text { yield variance }\end{array}$ & $\Delta \bar{A} \Delta \mathrm{V}(\mathrm{Y})$ & 0.81 \\
\hline $\begin{array}{l}\text { Interaction between changes in yields and area } \\
\text { variance }\end{array}$ & $\Delta \bar{Y} \Delta \mathrm{V}(\mathrm{A})$ & 18.31 \\
\hline $\begin{array}{l}\text { Interaction between changes in mean area and } \\
\text { yield and changes in area-yield covariance }\end{array}$ & $\Delta \bar{A} \Delta \bar{Y} \operatorname{cov}(\mathrm{A})$ & -1.98 \\
\hline Change in residual & $\Delta \mathrm{R}$ & 53.44 \\
\hline Total & - & 100.00 \\
\hline
\end{tabular}

On the other hand, high growth with medium instability in productivity of cotton is a relatively desirable situation which is noticed during the Overall Period. Similarly, medium growth with low instability in case of area, production and productivity of cotton observed during Post-Liberalization Period has all relatively better impact of liberalization on the production and productivity of cotton.

These findings are in conformity with those of Reddy et al., (2011) who observed that the cotton acreage in Gujarat increased at the rate of 2.34 per cent per annum while production and productivity increased at the rate of 7.77 and 5.30 per cent per annum during (1980-81 to 2010-11).

\section{Instability in production}

The pure effect of change in the mean yield, change in mean area, the effect of interaction between changes in mean area and mean yield and the change in covariance between area and yield were analysed by using Hazell's 
decomposition technique. The decomposition analysis was carried out and the percentage contribution of each component towards the change in average production of long staple cotton was estimated.

In order to examine the sources of instability more precisely, the change in variance in production for each crop group was decomposed into several components using Hazel's (1982) decomposition model. To apply Hazell's variance decomposition method, the total time span covered by the data has been divided into two periods. The first period covered 18 years from 1980-81 to 1997-98 and the second period also covered 18 years from 1998-99 to 2015-2016. Data on yield and area of long staple cotton were detrended separately for each period using linear trends. For each variable, the residual of the trend equation was added to the mean of the data series to generate detrended data centered on the mean. The detrended production was obtained by multiplying detrended yield and detrended area. The final analysis was conducted using these detrended data. The sources of variance in long staple cotton production are represented in the Table 6.

Fluctuations in long staple cotton production of Gujarat for the period 1980-81 to 2015-16 are analysed. Fluctuations in crop output may cause price instability, which in turn, may further adversely affect growth in crop yield, employment and income distributions. It is, therefore, necessary to take appropriate measures to stabilize agricultural prices and agricultural production. Fluctuations in crop yield particularly in the long staple cotton happen to be a regular phenomenon in Gujarat agriculture. This could be attributed mainly to the dependence on rainfall for the cultivation of crop in the state of Gujarat. The abnormal situation of rainfall was observed in the year 1991, 1995, 1999 and 2000. Therefore, an attempt has been made to analyse the extent and source of instability in the production of long staple cotton in the Gujarat state. It can be concluded that in the Pre-Liberalization Period, fluctuation in production as well as productivity of crops is higher than the PostLiberalization Period.

From the above discussion, it has been found that there exists a considerable variation in the production of long staple cotton in Gujarat. In this section, an attempt has been made to find out the possible sources that causes variance in the production of long staple cotton. The variance of production has been decomposed into area variance, productivity variance and area-productivity co-variance for long staple cotton and also for different time period separately.

In Gujarat, yield variance was the main contributor to the production variance in both Period I (50.9\%) and Period II (83.34\%). Area-yield covariance was the next source of variance in production during Period I (43.21 $\%)$ and Period II (9.9 \%) while area variance was the third source of variance in Period I $(28.34 \%)$ and Period II $(7.81 \%)$. From the results, it is observed that yield variance was the main source contributing to the variance in long staple cotton production in Gujarat state. The results of this study are in conformity with Singh et al., (2014) who studied the instability in rice production in Gujarat. They found that yield variance accounted for 66.17 per cent of total variance in rice production for the state, and further, they concluded that the change in yield has been the dominant source of total variation in production of rice in the state as well as in selected districts. These findings are also supported by Tiwari (2014) who in his study revealed that in Madhya Pradesh at the overall study period, the change in yield was the major source of output growth of cotton. He observed that in overall period 70 per cent of 
production growth was due to yield effect, whereas area effect was only 14 per cent.

The method to partition the changes in variance of production (V (Q)) between the first and the second periods into its constituent parts was constructed and the results are given in the Table 7 . It is evident from the table that the interaction between changes in yields and area variance accounted for the largest shares of changes in variance of production for long staple cotton. They accounted for 18.31 per cent of total long staple cotton production. The changes in mean yield showed 14.78 per cent of the changes in total variance of production. The proportion of interaction between changes in mean yield and mean area accounted for 3.24 per cent of the increase in the variance of total long staple cotton production.

A perusal of the table indicated that the changes in the mean area is also an important contributing factor to the changes in variance of production that registered the fourth largest shares of changes in total production for long staple cotton. They accounted for 9.52 per cent of total long staple cotton production. The interaction between changes in mean area and yield variance has less effect as they jointly contributed 0.81 per cent of the changes in total variance of production. Changes in the residual terms were important in explaining the changes in the variance of crop production in case of long staple cotton $(53.44 \%)$.

These results are akin to those of Samuel, (2011) who in his study found that major contributor to the variability in the country's cotton production was the change in yield variance accounting for 34.31 per cent and much of this came from change in yield variance in Maharashtra and Gujarat.

It can be concluded that growth fluctuations in terms of area, production, and productivity in Overall Period were found to be greater than Pre-Liberalization, Liberalization and Post-Liberalization Periods. In terms of percentage change, production noticed the highest per cent change during PostLiberalization Period over Pre-Liberalization Period (538.23\%), followed by productivity $(229.46 \%)$ and area $(95.37 \%)$. The highest instability was observed in production (43.97\%) during Overall Period. The highest compound growth rate $(7.50 \%$ / annum) was noticed in production during Overall Period and the results were statistically significant. The area under cotton production showed the highest compound growth rate $(3.84 \%$ / annum) during Liberalization Period. The results revealed that the area expansion under cotton led to increase cotton production during Post-Liberalization Period. But in case of the overall period, area and yield contributed jointly for the significant increase in cotton production. Hence, it is important to focus on yield rising through the increased use of agro-advisory services and provision of institutional support to farmers. The results of the decomposition analysis revealed that the change in mean production of long staple cotton was mainly due to the interaction between changes in yields and area variance as well as change in mean yield. It can be concluded that the future development programmes should envisage on stabilization of yield for bringing stabilization in production of the crop.

\section{References}

Anonymous, 2017. Ministry of Agriculture \& Farmers' Welfare, Department of Agriculture, Cooperation \& Farmers Welfare, Directorate of Cotton Development Government of India. Status Paper of Indian Cotton. Maharashtra, Director of Publications, $211 \mathrm{p}$.

Ardeshna, N. J., Dhandhalya, M. G., Swaminathan, B. and Purohit, V. L. 
2017. Contemporary dynamics in growth and instability in area, production and productivity in major cotton producing states of India. AGRES-An International e. Journal. 6(3): 531-539.

Hazell, P.B. R. 1982. Instability in Indian foodgrain production. Research Report 30, International Food Policy Research Institute, Washington, D. C., USA.

Mayilsami, K. and Selvaraj, A. 2016. Growth of cotton cultivation: A study in Tamil Nadu. Imperial Journal of Interdisciplinary Research (IJIR). 2(11): 1-5.

Mehta, N. 2012. Performance of crop sector in Gujarat during high growth period: Some explorations, Agricultural Economic Research Review. 25(2): 195204.

More, S.S.; Singh, N. and Leua, A. 2017. Performance of cotton in Gujarat: A long term critical analysis. Journal of Cotton Research and Development. 31(1): 157-163.

Nandamohan, V. and Sunny, G. 1993. Growth and instability in rubber plantation industry in India. Productivity. 34(3): 504-509

Reddy, A. R., Yelekar, S. M., Petkar, R. B. and Anuradha, N. 2011. Total factor productivity of cotton in Gujarat. World Cotton Research Conference on Technologies for Prosperity Mumbai, India. 7-11 November 2011. 76: 454460.

Samuel, J. 2011. Impact of WTO on the production and export of Indian cotton- an econometric analysis. Ph.D. Thesis (Unpublished). University of Agricultural Sciences, Dharwad.

Samuel, J., Basavaraja, H., Pushpanjali and Rejani, R. 2015. Production, growth and export competitiveness of raw cotton in India-An economic analysis. Agricultural Research \& Technology. 1(1): $1-5$.

Sharma, A. 2015. Growth and variability in area, production and yield of cotton crop. International Journal of Agriculture Innovations and Research. 4(3): 509-511.

Singh, N.; Dikshit, A.K.; Reddy, B.S. and Kuthe, S.B. 2014. Instability in rice production in Gujarat: A decomposition analysis. Asian Journal of Economics and Empirical Research. 1(1): 6-9.

Singh, S. P.; Jena, P.S. and Singh, N. K. 2013. Cotton production and environmental sustainability in India. Pp 1-200. Cuts International. Jaipur Printers Private Limited, Jaipur.

Suresh, A., Palanisamy, R., Samuel, J. and Wankhade, S. 2013. Impact of technology and policy on growth and instability of agricultural production: the case of cotton in India. Indian Journal of Agricultural Sciences. 83(8): 939-948.

Tiwari, S. 2014. An analysis of growth and instability of cotton production in Madhya Pradesh. M.Sc. (Agri.) Thesis (Unpublished). R.A.K. College of Agriculture, Sehore.

\section{How to cite this article:}

Daud Mohammad, R.L. Shiyani and Ardeshna, N.J. 2018. Growth Dimensions of Long Staple Cotton Area, Production and Yield in Gujarat, India. Int.J.Curr.Microbiol.App.Sci. 7(05): 2993-3005. doi: https://doi.org/10.20546/ijcmas.2018.705.348 